\title{
Assessing the impact of the Provincial Reimbursement Scheme on the use of Targeted Anticancer Medications in Zhejiang, China: A Controlled Interrupted time-series Analysis
}

\section{Cong Huang}

Peking University School of Pharmaceutical Sciences

\section{Carolina Oi Lam Ung}

University of Macau Institute of Chinese Medical Sciences

Haishaerjiang Wushouer

Tsinghua University School of Medicine

\section{Ziyue Xu}

Peking University School of Pharmaceutical Sciences

\section{Yichen Zhang}

Peking University School of Pharmaceutical Sciences

Xiaodong Guan ( $\nabla$ guanxiaodong@pku.edu.cn )

Department of Pharmacy Administration and Clinical Pharmacy, School of Pharmaceutical Sciences, Peking University https://orcid.org/0000-0002-1290-3827

\section{Luwen Shi}

Peking University School of Pharmaceutical Sciences

\section{Research}

Keywords: Provincial reimbursement, Targeted anticancer medications, Interrupted time-series

Posted Date: March 25th, 2020

DOI: https://doi.org/10.21203/rs.3.rs-18436/v1

License: (c) (i) This work is licensed under a Creative Commons Attribution 4.0 International License. Read Full License 


\section{Abstract}

Background: High prices of targeted anticancer medications (TAMs) subject patients to extreme financial burden. To alleviate problems with access and affordability, 6 TAMs were newly listed in the Provincial Reimbursement Drug List (PRDL) in Zhejiang, China in February 2015. To evaluate the implementation of the PRDL policy, this study examined differences in the hospital purchasing volume (HPV) and the hospital purchasing spending (HPS) of 6 listed TAMs preand post-enlistment and comparing with 4 other unlisted TAMs.

Methods: Interrupted time-series analysis was employed using the pharmaceutical procurement data of 6 newly listed TAMs (study group) and 4 unlisted TAMs (control group) from 22 tertiary hospitals in Zhejiang, China dated between January 2014 and March 2017.

Results: After February 2015, the average HPV per month increased significantly by 34.6 defined daily doses (DDDs) $(p<0.001)$ and the average HPS per month increased significantly by USD $6614.9(p<0.001)$ for the listed TAMs in the study group ( $n=6)$; neither the average HPV nor the average HPS changed significantly for the unlisted TAMs in the control group $(n=4)$. Although only 4 of the 6 listed TAMs exhibited significant decrease in the monthly HPV and HPS individually, the daily cost of each TAM decreased after enlistment.

Conclusions: The PRDL policy has shown positive effect on promoting the access to and improving patients' affordability of TAMs in Zhejiang. The government should conduct further price negotiations and include more TAMs with clinical benefits into reimbursement schemes to relief patients' financial burden and promote access.

\section{Introduction}

Cancer has been the leading cause of death and a major public health problem in China with increasing incidence and mortality. $(1,2)$ In 2015, about 4 million new cancer cases were reported, of which 2.3 million were new cancer deaths, (3) ranking first of major disease mortality. (4) Lung cancer ranks the first in the incidence of cancer in China, followed by gastric cancer, colorectal cancer, and liver cancer. (3)

Anticancer medications are important part of cancer treatment. Although anticancer medications are the key to gains in overall survival for a patient with cancer, their use may subject the patient to an extreme financial burden due to high prices. (5) Especially for targeted anticancer medications (TAMs), high prices have raised major concerns over their affordability. (6) Related studies showed that high medication cost of cancer has caused a serious economic burden on patients in China, especially for the 4 most common cancers (lung cancer, gastric cancer, colorectal cancer, and liver cancer). $(4,7-10)$

Adequate health insurance coverage of anticancer medications could promote access and better outcomes for cancer patients. (11-13) By the end of 2018, $94 \%$ of the population in China had been covered by Basic Medical Insurance (BMI). (1) In November 2009, the Ministry of Human Resources and Social Security (MOHRSS) issued the National Reimbursement Drug List (NRDL) (2009 Edition) including 102 anticancer medications, marking a crucial step in improving the coverage of anticancer medications in China. (14) Since then, some provinces and cities continued to include expensive anticancer medications into their Provincial Reimbursement Drug List (PRDL) according to local needs and fundraising levels. However, there is a lack of evidence available for decision makers about the impact of the PRDL policy on the use and spending of these medications after enlistment in the provincial reimbursement schemes. (15) In February 2015, Zhejiang Province Human Resources and Social Security (HRSS) department announced the enlistment of 15 expensive medications in the PRDL of Zhejiang after price negotiations. (16) Six of them were TAMs which included rituximab, trastuzumab, imatinib, gefitinib, nimotuzumab and cetuximab. The enlistment allowed the hospitals in Zhejiang to procure the listed mediations at the provincially negotiated prices. 
In order to evaluate the implementation of the government reimbursement policy, this study examined the differences in the hospital purchasing volume (HPV) and the hospital purchasing spending (HPS) of 6 listed TAMs pre- and postenlistment and in comparison with 4 other unlisted TAMs in Zhejiang, China.

\section{Method \\ Study design}

We used interrupted time series (ITS), the strongest quasi-experimental design (17) to analyze changes of medication use following the implementation of PDRL policy. The enlistment announcement of 6 TAMs was made on February 5, 2015 and thus we selected February 2015 as the breakpoint. To strengthen our design, in addition to the 6 TAMs newly listed in the PRDL in the study group, we selected 4 other unlisted TAMs in the Zhejiang reimbursement scheme as the control group (bevacizumab, erlotinib, bortezomib, recombinant human endostatin) (see Supplementary Table 1). We hypothesized that the impact on the HPV and the HPS of the listed TAMs in the study group would be different before and after the breakpoint, and from the unlisted TAMs in the control group.

\section{Data Sources}

We used the data from China Medicine Economic Information (CMEI), a large database of public hospital medication procurement records in mainland China. (18) We extracted data of the 6 TAMs in the study group and the 4 TAMs in the control group purchased by 22 tertiary hospitals from Zhejiang province between January 2014 and March 2017. Aggregated procurement data included the HPV and the HPS of the TAMs selected in this study, as well as their dosage form, strength, purchase time, the Anatomical Therapeutic Chemical (ATC) code (19) and manufacturer. Detailed information about the 6 listed TAMs in the study group was provided in Table 1. Ethical approval was not required according to the relevant requirements for conducting this type of survey in China. 
Table 1

Descriptive information of 4 TAMs unlisted in PRDL of Zhejiang

\begin{tabular}{|c|c|c|c|c|c|c|c|}
\hline $\begin{array}{l}\text { Generic } \\
\text { name }\end{array}$ & $\begin{array}{l}\text { Brand } \\
\text { name }\end{array}$ & $\begin{array}{l}\text { Date of } \\
\text { NMPA } \\
\text { approval }\end{array}$ & $\begin{array}{l}\text { Marketing } \\
\text { Authorisation } \\
\text { Holder }\end{array}$ & Strength & DDD † & $\begin{array}{l}\text { Thetapeutic } \\
\text { Class } \ddagger\end{array}$ & $\begin{array}{l}\text { ATC } \\
\text { code }\end{array}$ \\
\hline \multirow[t]{2}{*}{ Bevacizumab } & \multirow[t]{2}{*}{ Avastin } & \multirow[t]{2}{*}{2010.2 .26} & \multirow[t]{2}{*}{$\begin{array}{l}\text { Roche } \\
\text { Diagnostics } \\
\text { GmbH }\end{array}$} & \multirow[t]{2}{*}{100 mg/4 ml } & \multirow[t]{2}{*}{$50 \mathrm{mg}$} & $\begin{array}{l}\text { Metastatic } \\
\text { colorectal } \\
\text { cancer; }\end{array}$ & \multirow[t]{2}{*}{ L01XC07 } \\
\hline & & & & & & $\begin{array}{l}\text { Lung } \\
\text { cancer }\end{array}$ & \\
\hline Erlotinib & Tarceva & 2006.4 .6 & $\begin{array}{l}\text { Delpharm } \\
\text { Milano S.r.l. }\end{array}$ & 100 mg & 150 mg & $\begin{array}{l}\text { Lung } \\
\text { cancer }\end{array}$ & L01XE03 \\
\hline \multirow[t]{2}{*}{ Bortezomib } & \multirow[t]{2}{*}{ Velcade } & \multirow[t]{2}{*}{2005.2 .21} & \multirow{2}{*}{$\begin{array}{l}\text { BSP } \\
\text { Pharmaceuticals } \\
\text { S.p.A. }\end{array}$} & \multirow[t]{2}{*}{$1.0 \mathrm{mg}$} & \multirow[t]{2}{*}{$0.21 \mathrm{mg}$} & $\begin{array}{l}\text { Multiple } \\
\text { myeloma; }\end{array}$ & \multirow[t]{2}{*}{ L01XX32 } \\
\hline & & & & & & $\begin{array}{l}\text { Lymphoma } \\
\text { mantle cell }\end{array}$ & \\
\hline $\begin{array}{l}\text { Recombinant } \\
\text { Human } \\
\text { Endostatin }\end{array}$ & Endostar & 2005.9.12 & Simcere Pharma & $15 \mathrm{mg} / 3 \mathrm{ml}$ & $8.5 \mathrm{mg}$ & $\begin{array}{l}\text { Lung } \\
\text { cancer }\end{array}$ & l \\
\hline \multicolumn{8}{|c|}{$\begin{array}{l}\text { TDDD: Defined Daily Dose, is calculated for each product in consideration of the dosage regimen recommended in } \\
\text { the manufacturers' instructions of products, as approved by National Medical Products Administration (NMPA). }\end{array}$} \\
\hline
\end{tabular}

\section{Outcome Measures}

The primary outcomes we included were the average HPV per month and the average HPS per month of the study group and the control group, as well as the HPV per month and the HPS per month for each of the TAMs in the study group. Secondary outcome of interest was the average daily cost (cost of Defined Daily Dose, DDDc) for the 6 TAMs in the study group. The Defined Daily Dose (DDD) in our study referred to the daily amounts based on dosage regimen recommended in the manufacturers' instructions, as approved by National Medical Products Administration (NMPA). (20)The volume in HPV was defined as the numbers of DDD (DDDs). The spending in HPS was indicated by the hospital spending on each medication per month. The HPV per month was reported in the US dollar (US\$1= $¥ 6.1428$ based on the 2014 exchange rate (21) ) after adjusted to January 2014 using the medical care component of the Consumer Price Index (CPI). (22)

\section{Statistical analysis}

We assessed the outcomes over time for the 6 newly listed TMAs in the study group and the 4 unlisted TAMs in the control group. ITS model with a single breakpoint was formulated to estimate the impacts of enlistment on monthly average HPV and HPS. The regression equation is as follows:

$Y_{\text {it }}=\beta_{0}+\beta_{1} *$ time $_{t}+\beta_{2} *$ level $_{t}+\beta_{3} *$ trend $_{t}+\varepsilon_{\text {it }}$ 
$Y_{t}$ represented the spending or volume at time t. $\beta_{0}$ estimated the level of $Y_{t}$ at the beginning of the observation period; $\beta_{1}$ estimated the trend of the outcomes in the pre-intervention periods; $\beta_{2}$ estimated the level change of the outcomes immediately following the policy; $\beta_{3}$ estimated the trend change after the intervention; $\varepsilon_{i t}$ represented the random error at time t. We presented changes in the level or trend of the average HPV per month and the average HPS per month. Total changes by the end of observation (12 months after implementation) of the outcomes were also reported.

The Durbin-Watson statistic was used to test for a serial autocorrelation of the error terms in the regression models. (23) We used the Cochrane-Orcutt auto-regression procedure to correct for first order serially correlated errors when needed. (24) All statistical analysis was performed using STATA/SE V.15.0.

\section{Results}

\section{The changes in the average HPV per month and HPS per month of listed and unlisted TAMs}

The average HPV per month and the average HPS per month of the 6 listed TAMs in the study group increased significantly after February 2015, while there were no statistically significant changes in the average HPV per month nor the average HPS per month for 4 unlisted TAMs in the control group (Fig. 1; Table 2). The average HPV per month of the listed TAMs in the study group experienced a significant level increase of 34.6 DDDs $(p<0.001)$ following the enlistment while TAMs in control group showed no statistical changes in the HPV level or trend. Similarly, there was a significant increase of $\$ 6614.9(p<0.001)$ in the level of the average HPS per month for the listed TAMs in the study group, and no significant changes were observed in the control group. At the end of observation period (12 months after policy implementation), an estimated increase of 50.9 DDDs $(p<0.001)$ in the average of HPV per month and $\$ 8470.1$ $(p<0.001)$ in the average of HPS per month of the 6 listed TAMs in the study group was observed.

Table 2

Estimates from ITS models of changes in the average HPV and HPS for two groups

\begin{tabular}{|c|c|c|c|c|c|}
\hline & Baseline level & $\begin{array}{l}\text { Baseline } \\
\text { trend }\end{array}$ & $\begin{array}{l}\text { Level } \\
\text { change }\end{array}$ & $\begin{array}{l}\text { Trend } \\
\text { change }\end{array}$ & $\begin{array}{l}\text { Absolute } \\
\text { change§ }\end{array}$ \\
\hline \multicolumn{6}{|c|}{$\begin{array}{l}\text { Average Hospital Purchasing Volume (DDD) per } \\
\text { month }\end{array}$} \\
\hline Study group $†$ & $36.6 * \star \star$ & -0.7 & $34.6 * \star \star$ & 1.4 & $50.9 * \star \star$ \\
\hline Control group $\neq$ & $12.7^{\star * \star}$ & -0.2 & -3.1 & 0.5 & 2.6 \\
\hline \multicolumn{6}{|c|}{ Average Hospital Purchasing Spending (USD) per month } \\
\hline Study group & $6761.6 * \star *$ & $-143.0 *$ & $6614.9 * \star \star$ & 154.6 & $8470.1^{\star \star \star}$ \\
\hline Control group & $2093.9 * * *$ & 20.5 & -766.2 & 48.9 & -179.7 \\
\hline \multicolumn{6}{|c|}{$*, p<0.05 ; * *, p<0.01 ; * \star *, p<0.001$} \\
\hline \multicolumn{6}{|c|}{ †Study group: 6 targeted anticancer medications newly listed in provincial reimbursement scheme in Zhejiang } \\
\hline \multicolumn{6}{|c|}{ ¥Control group: 4 targeted anticancer medications unlisted in provincial reimbursement scheme; } \\
\hline \multicolumn{6}{|c|}{$\S A$ bsolute change: changes at 12 months after the policy implementation } \\
\hline
\end{tabular}




\section{The changes in the average daily cost of listed and unlisted TAMs}

The average daily cost of the 6 listed TAMS in the study group declined after the policy implementation (Fig. 2). Before February 2015, the daily costs of TAMs from both groups were stable. After enlistment in the provincial reimbursement scheme in Zhejiang, the daily cost of the 6 listed TAMs in the study group experienced an abrupt decrease while no significant change was observed about those in the control group.

The changes in the HPV per month, HPS per month and daily cost of listed TAMs

Each of the listed TAMs in the study group experienced significant increases in the HPV per month and the HPS per month after enlistment on the PRDL except for nimotuzumab and imatinib (Fig. 3; Table 3). The HPV per month of trastuzumab increased by 172.8 DDDs $(p<0.001)$ by the end of observation. Other listed TAMs like gefitinib $(80.0$ DDDs, $p<0.05)$, rituximab (11.7 DDDs, $p<0.05)$ and cetuximab (6.3 DDDs, $p<0.05)$ also increased significantly in HPV per month. Similarly, there were significant increases in the HPS per month for these 4 listed TAMs with trastuzumab exhibiting the most increase in spending $(\$ 23187.6, p<0.001)$. As for nimotuzumab and imatinib, there was no statistically significant change in HPV or HPS even 12 months after enlistment in the provincial reimbursement scheme.

Table 3

Estimates from ITS models of changes in the HPV and HPS of the listed TAMs

\begin{tabular}{|c|c|c|c|c|c|c|}
\hline & \multicolumn{3}{|c|}{$\begin{array}{l}\text { Hospital Purchasing Volume (DDD) per } \\
\text { month }\end{array}$} & \multicolumn{3}{|c|}{$\begin{array}{l}\text { Hospital Purchasing Spending (USD) per } \\
\text { month }\end{array}$} \\
\hline & $\begin{array}{l}\text { Level } \\
\text { change }\end{array}$ & $\begin{array}{l}\text { Trend } \\
\text { change }\end{array}$ & $\begin{array}{l}\text { Absolute } \\
\text { change }\end{array}$ & $\begin{array}{l}\text { Level } \\
\text { change }\end{array}$ & $\begin{array}{l}\text { Trend } \\
\text { change }\end{array}$ & $\begin{array}{l}\text { Absolute } \\
\text { changet }\end{array}$ \\
\hline Gefitinib & 31.8 & 4 & $80.0^{\star}$ & 2302.6 & 265.7 & $5491.4^{*}$ \\
\hline Rituximab & $8.0 *$ & 0.3 & $11.7^{*}$ & $7703.2^{\star}$ & 207.6 & 10194.3* \\
\hline Nimotuzumab & 35.3 & -2.4 & 6.4 & 4316 & -466 & -1275.7 \\
\hline Trastuzumab & $115.6 * * *$ & 4.8 & $172.8^{\star \star *}$ & $17588.1^{\star \star \star}$ & 466.6 & $23187.6 * \star *$ \\
\hline Cetuximab & 6.6 & -0.03 & $6.3^{\star}$ & 4859.5 & -48.3 & 4279.8* \\
\hline Imatinib & 5.4 & 0.2 & 7.7 & 923.4 & 17.2 & 1129.5 \\
\hline \multicolumn{7}{|c|}{$*, p<0.05 ; * \star, p<0.01 ; * \star *, p<0.001$} \\
\hline
\end{tabular}

The daily cost of each of the 6 listed TAMs in the study group all declined following the PRDL policy implementation (Fig. 3). The daily cost of each of the 6 listed TAMs was stable before February 2015 and remained so until an abrupt decrease observed after March 2015. Out of the 6 listed TAMs, the cut in the daily cost of nimotuzumab was the greatest (from about $\$ 160$ to $\$ 120$ ).

\section{Discussion}

Our study showed that, after enlistment on the PRDL, the average HPV per month and the average HPS per month of the anticancer medications selected in this study increased significantly in Zhejiang province. Furthermore, the average daily cost of these newly listed anticancer medications declined shortly after the enlistment and remained stabilized 
overtime. These findings suggested that the PRDL policy was successful at encouraging the use of anticancer medications, promoting the access and improving patients' affordability.

The time of the PRDL policy implementation in this study was set as February 2015 when 6 TAMs were newly enlisted on the PRDL in Zhejiang province. The average of the HPV per month for the 6 listed TAMs increased significantly after the enlistment and throughout the study period. This shows that the provincial reimbursement scheme was an effective way to promote the use of anticancer medications, which is consistent with previous studies. $(15,25,26)$ This is especially evident when comparing gefitinib (listed TAM) and erlotinib (unlisted TAM) as shown in this study. Both of these medications were first-line TAMs for non-small-cell lung cancer patients with somatic EGFR mutations in China. (27) Erlotinib was also a second-line TAM after failure of at least one prior chemotherapy regimen. However, we found that the HPV per month and the HPS per month of gefitinib increased significantly after enlistment of the PRDL while there was no change for erlotinib. Such differences suggest that the tertiary hospitals had a higher tendency to purchase medications listed in the provincial reimbursement scheme emphasizing the positive role that the PRDL policy may play in encouraging the use of anticancer medications.

TAMs have been the focus of cancer drug development over the past two decades, $(28,29)$ which meanwhile have raised major concerns over their affordability due to skyrocketing prices. (30) In this study, we found that the daily cost of the 6 expensive TAMs successfully decreased after enlistment, which reflected the improvement in patients' affordability. According to the reimbursement policy, when patients were prescribed with listed medications, after a deductible of CNY 20000 (USD 3077), the provincial reimbursement scheme would help pay a pre-defined portion of the total amount of patient's payment (e.g. 70\% in Hangzhou, the capital city of Zhejiang province (31) ), and the patients would have to bear the remaining cost (e.g. $30 \%$ in Hangzhou). Listing of the medications on the reimbursement list can decrease patients' out-of-pocket spending. The policy relieved the economic burden of patients and improved access to expensive anticancer medications in Zhejiang province.

We have also identified 2 important factors when evaluating the implementation of the PDRL policy in this study: the availability of generic medicines and the time lag between policy issuance and implementation. At the individual level, not every anticancer medication showed significant increase in the HPV per month and the HPS per month following reimbursement inclusion. Imatinib (listed medication) included in our study was the branded originator which showed no significant change in terms of the HPV per month nor the HPS per month. Since patent protection of imatinib was expired before February 2015, generic of imatinib was already available locally marketed at a lower price compared to its originator. The availability of the generic medications would impact the use and cost of anticancer medications in China. $(18,32)$ Patients taking generic imatinib might not turn to branded imatinib even when the originator became listed on the PDRL.

Our study also found that, while the average HPV per month and the average HPS per month of the newly listed TAMs increased immediately after enlistment in February 2015, the average daily cost of these TAMs only declined after 2 months in April 2015. Each province had a medicine tender bidding center to select medicine manufacturers and to determine medicine prices for government-run healthcare institutions. (33) In Zhejiang, the HRSS department issued the enlistment announcement on February 4, but the prices of listed medications on medicine tender bidding center were only updated in April 2015 showing a 2-month lag period. (34) Although such delay due to policy coordination among departments may be inevitable, improved coordination and cooperation between related sectors were vital to achieve "health in all policies" in the most timely manner. (35) More effective mechanisms are needed to improve intersectoral coordination and shorten implementation delay between departments.

There were several limitations in this study. First, only patients from 22 of more than 130 tertiary hospitals (4) of Zhejiang province were included in our study, the findings of which were not able to fully reflect the monthly medication 
consumption and spending of all hospitals in the province; Second, there were related Patient Assistance Programs (PAPs) existing in China, like Iressa Means-Tested Drug Donation(36) for gefitinib. Low income patients who could not afford continuous treatment could receive free Iressa after paying for the first several courses of treatment. The influence of programs alike was not taken into account in our analysis. However, the number of patients who participate in PAPs was limited and almost $70 \%$ of medication sales in China occurred in hospitals. (37) Third, the data we used was from hospital procurement records, which did not directly reflect the access to medications at patient level. Further study is needed to evaluate patients' access to TAMs using claim data or prescription data. Patients in secondary hospitals should also be enrolled.

\section{Conclusion}

The PDRL policy has shown positive impact on promoting the use of anticancer medications and improving patients' affordability in Zhejiang province, China. After enlisting on the PDRL, the HPV per month and the HPS per month of expensive anticancer medication increased significantly at hospital level and thus the out-of-pocket expenses were reduced at patient level. However, further study with claim data or prescription data is needed to provide more evidence on how patients' access to different anticancer medication changes with provincial reimbursement inclusion policy. Our government should conduct further price negotiations and include more anticancer medications with clinical benefit into reimbursement schemes to relief patients' financial burden and promote access.

\section{Abbreviations}

\begin{tabular}{ll} 
TAM & Targeted Anticancer Medication \\
PRDL & Provincial Reimbursement Drug List \\
HPV & Hospital Purchasing Volume \\
HPS & Hospital Purchasing Spending \\
USD & United States dollar \\
BMI & Basic Medical Insurance \\
MOHRSS & Ministry of Human Resources and Social Security \\
HRSS & Human Resources and Social Security \\
NRDL & National Reimbursement Drug List \\
ITS & Interrupted Time Series \\
CMEI & China Medicine Economic Information \\
ATC & Anatomical Therapeutic Chemical \\
DDD & Defined Daily Dose \\
NMPA & National Medical Products Administration \\
CPI & Consumer Price Index \\
CNY & Chinese yuan \\
PAP & Patient Assistance Program \\
\hline
\end{tabular}

\section{Declarations}




\section{Ethics approval and consent to participate}

Not applicable. The study was considered non-human subjects research by the Harvard Pilgrim Health Care Institutional Review Board. Ethical approval was not required according to the relevant requirements for conducting this type of survey in China.

\section{Consent for publication}

Not applicable.

\section{Availability of data and material}

The datasets used and/or analysed during the current study are available from the corresponding author on reasonable request.

\section{Competing interests}

The authors declare that they have no competing interests.

\section{Funding}

This study received no specific grant from any funding agency in the public, commercial or not-for-profit sectors.

\section{Authors' contributions}

All authors contributed to the study conception and design. Material preparation, data collection and analysis were performed by Xiaodong Guan, Cong Huang, Ziyue Xu and Yichen Zhang. The first draft of the manuscript was written by Cong Huang, Carolina Oi Lam Ung and Haishaerjiang Wushouer, all authors commented on previous versions of the manuscript. All authors read and approved the final manuscript.

\section{Acknowledgements}

We thank the staff of Chinese Pharmaceutical Association for their support and cooperation in data access and analysis.

\section{References}

1. National Health Commission. China health statistical yearbook 2018. Beijing: China Union Medical University Press: National Health Commission of the People's Republic of China; 2019.

2. Chen W, Zheng R, Baade PD, Zhang S, Zeng H, Bray F, et al. Cancer statistics in China, 2015. CA Cancer J Clin. 2016;66(2):115-32.

3. Zheng RS, Sun KX, Zhang SW, Zeng HM, Zou XN, Chen R, et al. [Report of cancer epidemiology in China, 2015]. Zhonghua zhong liu za zhi [Chinese journal of oncology]. 2019;41(1):19-28.

4. National Health Commission. China health statistical yearbook 2016. Beijing: China Union Medical University: National Health Commission of the People's Republic of China; 2017.

5. Carrera PM, Kantarjian HM, Blinder VS. The financial burden and distress of patients with cancer: Understanding and stepping-up action on the financial toxicity of cancer treatment. CA Cancer J Clin. 2018;68(2):153-65.

6. Shih YT, Xu Y, Liu L, Smieliauskas F. Rising Prices of Targeted Oral Anticancer Medications and Associated Financial Burden on Medicare Beneficiaries. Journal of clinical oncology : official journal of the American Society 
of Clinical Oncology. 2017;35(22):2482-9.

7. Zhang X, Liu S, Liu Y, Du J, Fu W, Zhao X, et al. Economic Burden for Lung Cancer Survivors in Urban China. International journal of environmental research and public health. 2017;14(3).

8. Li X, Cai H, Wang C, Guo C, He Z, Ke Y. Economic burden of gastrointestinal cancer under the protection of the New Rural Cooperative Medical Scheme in a region of rural China with high incidence of oesophageal cancer: crosssectional survey. Tropical medicine \& international health : TM \& IH. 2016;21(7):907-16.

9. Huang HY, Shi JF, Guo LW, Bai YN, Liao XZ, Liu GX, et al. Expenditure and financial burden for the diagnosis and treatment of colorectal cancer in China: a hospital-based, multicenter, cross-sectional survey. Chinese journal of cancer. 2017;36(1):41.

10. Qiu WQ, Shi JF, Guo LW, Mao AY, Huang HY, Hu GY, et al. Medical expenditure for liver cancer in urban China: A 10year multicenter retrospective survey (2002-2011). Journal of cancer research and therapeutics. 2018;14(1):163-70.

11. Ward E, Halpern M, Schrag N, Cokkinides V, DeSantis C, Bandi P, et al. Association of insurance with cancer care utilization and outcomes. CA Cancer J Clin. 2008;58(1):9-31.

12. Lee C, Sun H, Guan Q, Wasserman M. The Effect of China's Basic Medical Insurance Schemes on Health Service Utilization. Value in health : the journal of the International Society for Pharmacoeconomics and Outcomes Research. 2014;17(7):A428.

13. Yoruk BK. Health insurance coverage and health care utilization: Evidence from the Affordable Care Act's dependent coverage mandate. Forum for health economics \& policy. 2019;21(2).

14. Ministry of Human Resources and Social Security. National Reimbursement Drug List (NRDL) (2009 Edition) People's Republic of China2009 [Available from: http://www.gov.cn/gzdt/2009-11/30/content_1476934.htm.

15. Diao Y, Qian J, Liu Y, Zhou Y, Wang Y, Ma H, et al. How government insurance coverage changed the utilization and affordability of expensive targeted anti-cancer medicines in China: an interrupted time-series study. Journal of global health. 2019;9(2):020702.

16. Human Resources and Social Security Department. Inclusion of expensive medicines by the catastrophic health insurance program in Zhejiang: Zhejiang Province Human Resources and Social Security Department, China; 2015 [Available from: http://www.zjhrss.gov.cn/art/2015/2/5/art_1442944_18305524.html.

17. Wagner AK, Soumerai SB, Zhang F, Ross-Degnan D. Segmented regression analysis of interrupted time series studies in medication use research. Journal of clinical pharmacy and therapeutics. 2002;27(4):299-309.

18. Guan X, Tian Y, Ross-Degnan D, Man C, Shi L. Interrupted time-series analysis of the impact of generic market entry of antineoplastic products in China. BMJ open. 2018;8(7):e022328.

19. New ATC codes 2019 [Internet]. WHO Collaborating Centre for Drug Statistics Methodology. 2019 [cited September 23, 2019]. Available from:

https://www.whocc.no/atc_ddd_index/updates_included_in_the_atc_ddd_index/new_atc_codes_2019/.

20. Collection of Drugs Marketed in China [Internet]. National Medical Products Administration of the People's Republic of China. 2019 [cited September 23, 2019]. Available from: http://202-96-26-102.ipv6.nmpa.gov.cn/about/guide.

21. Time Series Data - Annual Data: Exchange Rate [Internet]. National Bureau of Staatistics of China. 2019 [cited September 23, 2019]. Available from: http://www.stats.gov.cn/english/Statisticaldata.

22. Time Series Data - Monthly Data: Consumer Price Index [Internet]. National Bureau of Staatistics of China. 2019 [cited September 23, 2019]. Available from: http://www.stats.gov.cn/english/Statisticaldata.

23. Durbin J, Watson GS. Testing for serial correlation in least squares regression. I. Biometrika. 1950;37(3-4):409-28.

24. Kutner M, Nachtsheim C, Neter J. Applied Linear Regression Models (4th edn): Irwin/McGraw-Hill: Chicago; 2004. 
25. Massard da Fonseca E, Bastos FI, Lopes G. Increasing Access to Oral Anticancer Medicines in Middle-Income Countries: A Case Study of Private Health Insurance Coverage in Brazil. Journal of global oncology. 2016;2(1):3946.

26. Mihajlovic J, Dolk C, Postma MJ. Reimbursement of Targeted Cancer Therapies Within Three Different European Health Care Systems. Value in health : the journal of the International Society for Pharmacoeconomics and Outcomes Research. 2014;17(7):A658-9.

27. Chinese Society of Clinical Oncology. CSCO Clinical Guidelines in Oncology Lung Cancer: Chinese Society of Clinical Oncology; 2018.

28. National Cancer Institute. Targeted Cancer Therapies 2019: National Cancer Institute; 2019 [Available from: https://www.cancer.gov/about-cancer/treatment/types/targeted-therapies/targeted-therapies-fact-sheet.

29. Sledge GW, Jr. What is targeted therapy? Journal of clinical oncology : official journal of the American Society of Clinical Oncology. 2005;23(8):1614-5.

30. Gyawali B, Sullivan R. Economics of Cancer Medicines: For Whose Benefit? The New bioethics : a multidisciplinary journal of biotechnology and the body. 2017;23(1):95-104.

31. Human Resource and Social Security Bureau. Inclusion of expensive medicines by the catastrophic health insurance program in Hangzhou: Hangzhou Municipal Human Resource and Social Security Bureau; 2015 [Available from: http://hrss.hangzhou.gov.cn/art/2015/9/10/art_1587913_28276248.html.

32. Regan TL. Generic entry, price competition, and market segmentation in the prescription drug market. International Journal of Industrial Organization. 2008;26(4):930-48.

33. Hu S. The Theory and practice of "Two-Invoice System" in the drug procurement. China Academic Journal Electronic Publishing House. 2017:8-10.

34. Provincial Center for Drug \& Medical Device Procurement. Inclusion of medicines listed in catastrophic health insurance program by online procurement catalog: Zhejiang Provincial Center for Drug \& Medical Device Procurement; 2015 [Available from: http://www.zjyxcg.cn/detail.html?infold=1897\&Catalogld=3.

35. Meng Q, Mills A, Wang L, Han Q. What can we learn from China's health system reform? BMJ (Clinical research ed). 2019;365:12349.

36. China Charity Federation. Iressa Means-Tested Drug Donation: China Charity Federation; 2012 [Available from: http://www.iressaccf.org.cn/Index.aspx.

37. Wan Q, H. ZY, F. WX. Results and Analysis of China National Health Accounts in 2013. Chinese Health Economics. 2015.

\section{Figures}



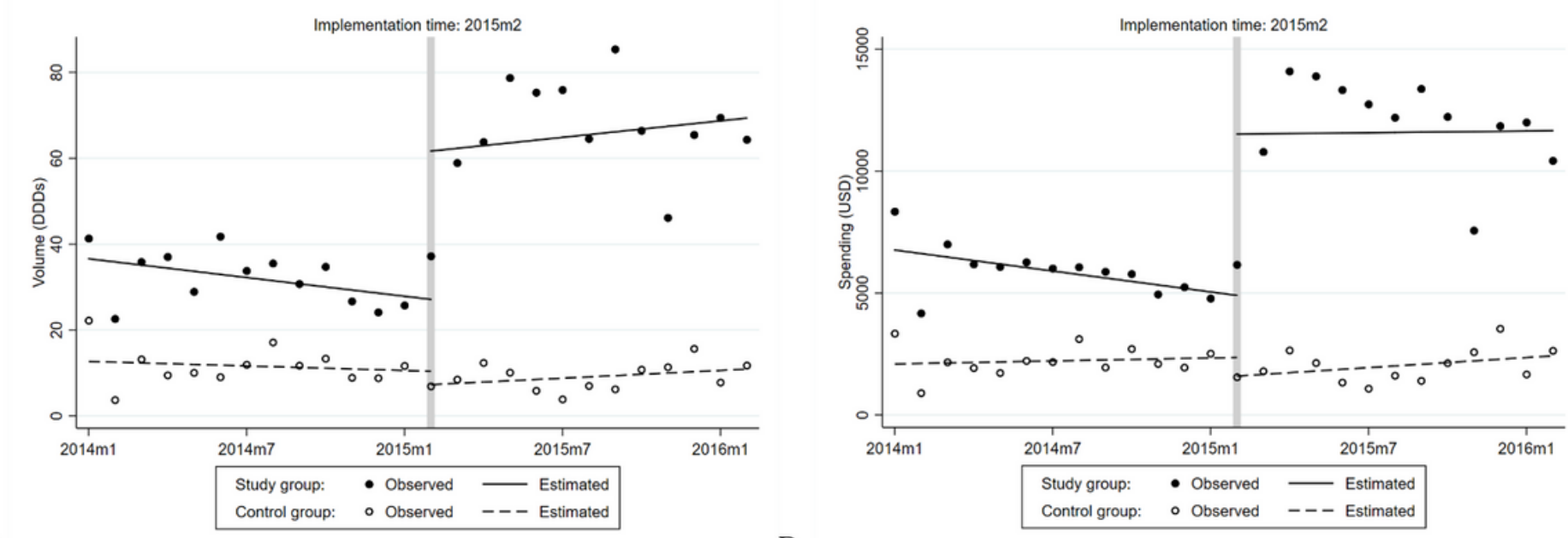

A

$\mathrm{B}$

\section{Figure 1}

Changes in the average purchasing volume and spending for two groups. Changes in the average Hospital Purchasing Volume per month (A) and the average Hospital Purchasing Spending per month (B) for the study group $(n=6)$ and the control group ( $n=4)$, 2014-2016.

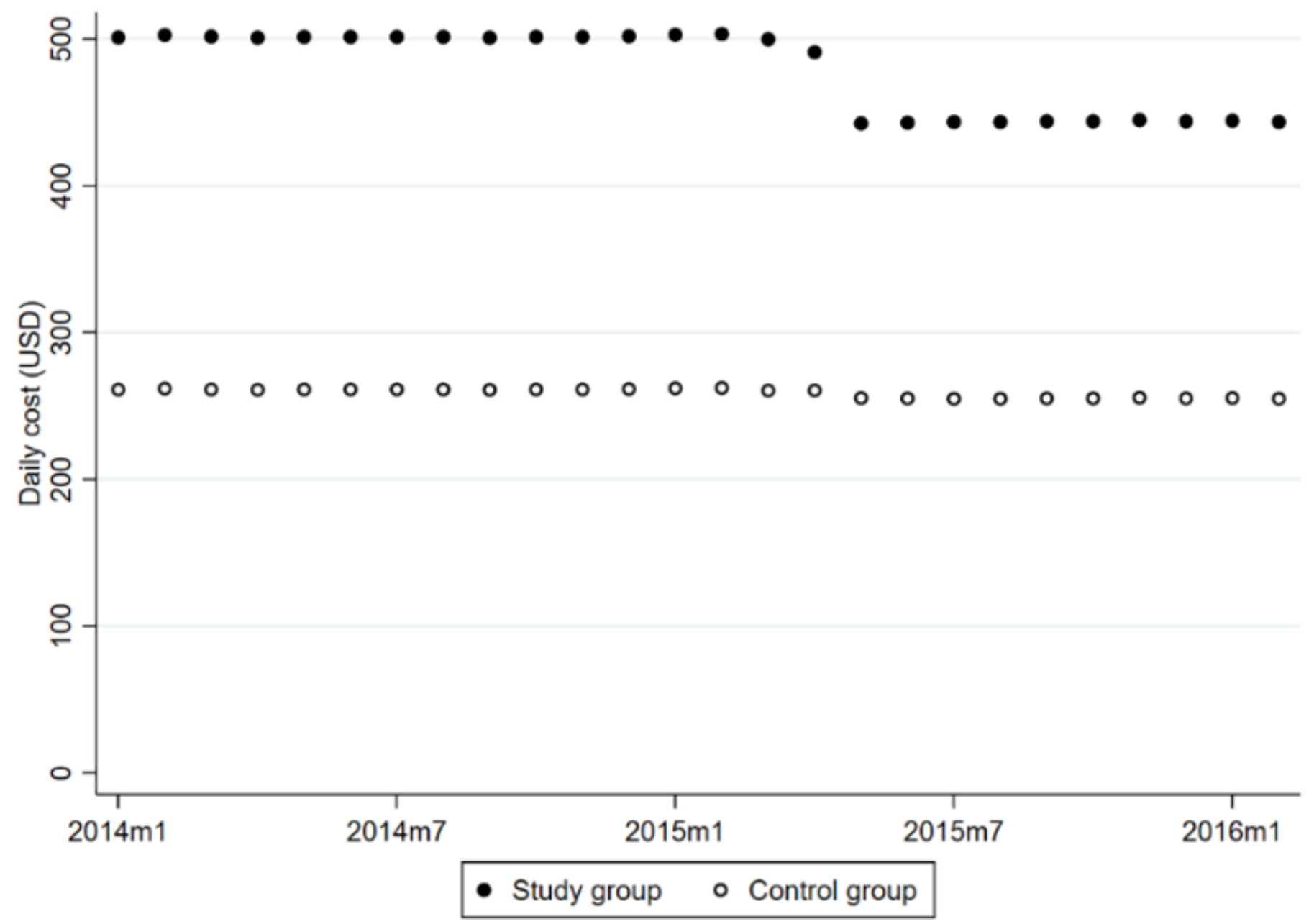

Figure 2 
Changes in the average daily cost for two group. Changes in the average daily cost between the study group $(n=6)$ and the control group $(n=4), 2014-2016$.
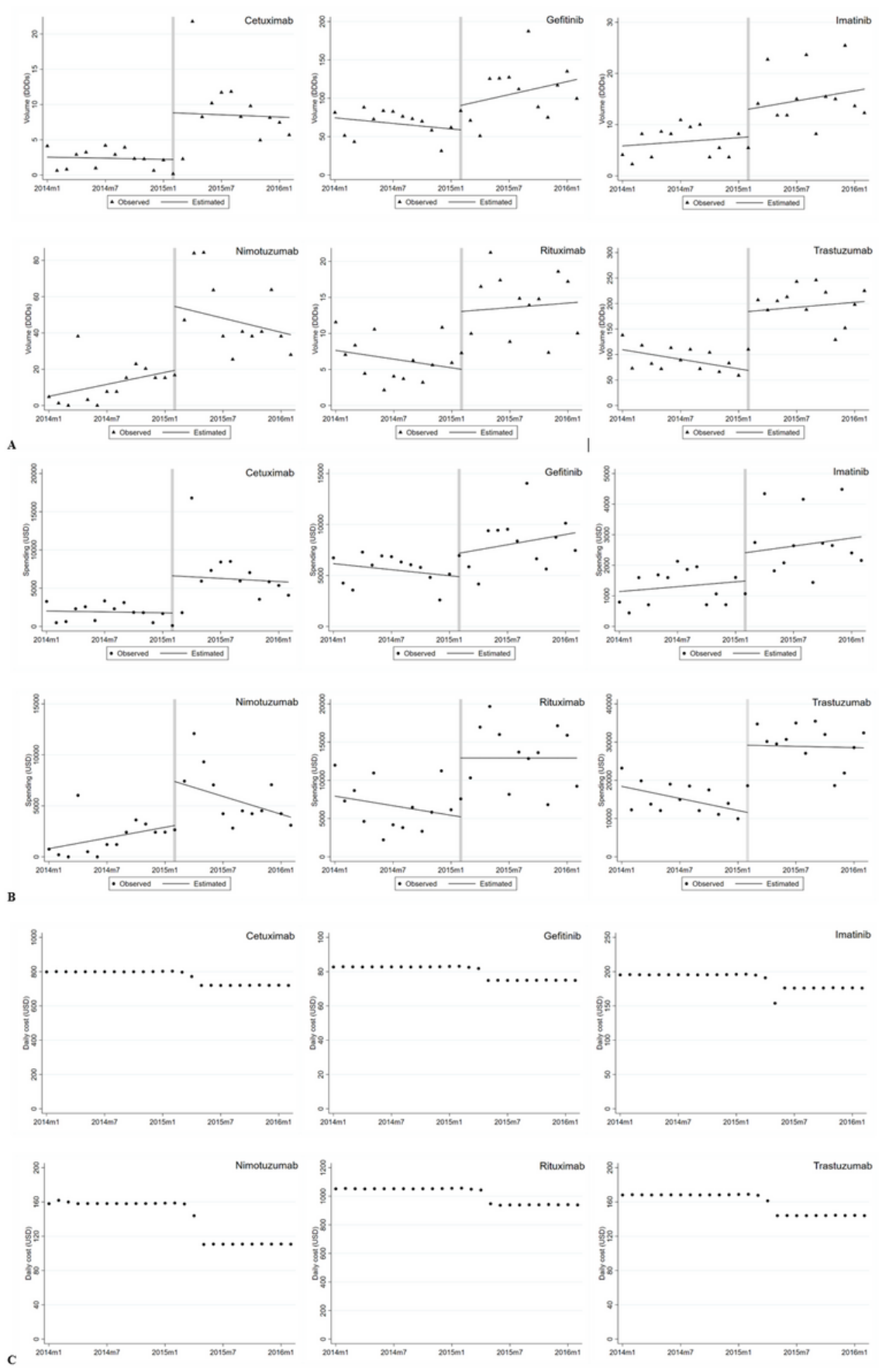

\section{Figure 3}

Changes in the purchasing volume and spending for listed TAMs. Changes in the Hospital Purchasing Volume per month (A), the Hospital Purchasing Spending per month (B) and the daily cost (C) of the 6 listed targeted anticancer medications, 2014-2016

\section{Supplementary Files}

This is a list of supplementary files associated with this preprint. Click to download. 
- SupplementaryTable1.xlsx

Page 14/14 